\title{
EL TRIBUNAL CONSTITUCIONAL PERUANO DURANTE LOS AÑOS 2014 Y 2015: BALANCE JURISPRUDENCIAL
}

\section{The Peruvian Constitutional Court between 2014 and 2015: Jurisprudential Analysis}

\author{
LUIS R. SÁENZ DÁVALOS \\ Academia de la Magistratura (Lima) \\ Isaenz_9@hotmail.com \\ LUIS ROEL ALVA' \\ Universidad San Ignacio de Loyola (Lima) \\ lvis.roelalva@gmail.com
}

Cómo citar/Citation

Sánez Dávalos, L. R. y Roel Alva, L. (2016).

El Tribunal Constitucional peruano durante los años 2014 y 2015 :

balance jurisprudencial.

Anuario Iberoamericano de Justicia Constitucional, 20, 589-628.

doi: http://dx.doi.org/10.18042/cepc/aijc.20.20

SUMARIO

I. CONSIDERACIONES PRELIMINARES II. EL PERIODO 2014: 1. Procesos constitucionales de tutela de derechos; 2 . Procesos constitucionales orgánicos. III. EL PERIODO 2015; 1. Procesos constitucionales de tutela de derechos; 2. Procesos constitucionales orgánicos. IV. BALANCE DE LA ACTUACION DEL NUEVO PLENO A LA LUZ DE SU JURISPRUDENCIA. V. BIBLIOGRAFÍA.

Luis R. Sáenz Dávalos es profesor de Derecho Constitucional y Derecho Procesal Constitucional en la Academia de la Magistratura. Secretario de la Asociación Peruana de Derecho Constitucional. Asesor jurisdiccional del Tribunal Constitucional.

Luis Roel Alva es profesor de Bases Legales en la Facultad de Derecho de la Universidad San Ignacio de Loyola. Magister en Derecho Constitucional por la Pontificia Universidad Católica del Perú. Asesor Jurisdiccional del Tribunal Constitucional. 


\section{CONSIDERACIONES PRELIMINARES}

El periodo correspondiente a los años 2014 y 2015 ha sido para el Tribunal Constitucional peruano de replanteamientos absolutos ${ }^{2}$.

En efecto, hacia el 21 de mayo de 2014, el Congreso de la República procedió a elegir a seis magistrados constitucionales, en reemplazo de aquellos otros cuyo periodo hace mucho que ya había expirado. De acuerdo con ello fueron designados los doctores Manuel Miranda Canales, Ernesto Blume Fortini, Carlos Ramos Núñez, José Luis Sardón de Taboada, Marianella Ledesma Narváez y Eloy Espinosa-Saldaña Barrera. Ellos sustituyeron en sus cargos a los salientes, Juan Vergara Gotelli, Ricardo Beaumont Callirgos, Fernando Calle Hayen, Carlos Mesía Ramírez, Gerardo Eto Cruz y Ernesto Álvarez Miranda. Solo Óscar Urviola Hani se quedó en el Tribunal por mantener a la fecha de designación aún vigente su mandato.

Es un hecho que la citada renovación venía siendo reclamada desde diversos sectores en el entendido de que el Pleno saliente venía experimentando un acentuado desgaste y, sobre todo, el embate crítico generado a raíz de las sentencias emitidas hacia el último tramo, algunas de las cuales y para ser consecuentes con la verdad, habían venido acompañadas de una fuerte polémica o debate. En vista de ello, la designación de los reemplazantes sería asumida como una oportunidad no solo para oxigenar el Colegiado con la presencia de nuevas personas, sino para retomar el prestigio institucional que en algún momento y de manera bastante sólida había tenido el Tribunal. De esta forma se vieron cifradas en el nuevo Pleno las mejores expectativas por parte de la opinión pública y ello se vio nítidamente reflejado en la empatía social y política que tal designación generó.

Durante los primeros meses del nuevo Pleno no hubo mayor referente crítico en torno de su funcionamiento probablemente como consecuencia del consabido periodo de gracia que tiene toda nueva conformación, a lo que cabe añadir que la producción jurisprudencial evidenciada por entonces (bastante escasa por cierto) se limitó a la publicación de aquellas sentencias que habían quedado pendientes del Pleno saliente y que no formaban parte del paquete de aquellas que, como ya se ha mencionado, ofrecían mayor discusión o controversia.

Las primeras clarinadas jurisprudenciales de la nueva conformación se verían reflejadas en algunas decisiones que intentarían marcar distancia de lo

2 En la selección de las sentencias utilizadas para redactar el presente trabajo hemos contado con el valioso concurso de la asesora del Tribunal Constitucional, doctora Carin Huancahuari Paucar. 
resuelto por el Pleno saliente a tal grado que se optaría, dentro del marco de alternativas previstas en el Código Procesal Constitucional, por corregir o dejar sin efecto algunas de sus decisiones o actuados procesales más polémicos en el entendido que se trataba de procesos aún no concluidos. Posteriormente, y a manera de hacer frente al problema de la sobrecarga pendiente, se adoptaría algún precedente que, según veremos más adelante, representaría un adelanto de la toma de posición que desde entonces ya empezaría a enunciarse en torno de la política jurisdiccional próxima a emprenderse.

Ya en el segundo año de la nueva conformación, el Colegiado empezaró a cobrar protagonismo propio, aunque este último, y salvo excepciones, estará caracterizado más que por la adopción de posturas garantistas frente a los casos, por una acentuada tendencia autorestrictiva, lo que traerá consigo y cada vez con mayor frecuencia la adopción de disidencias o posiciones singulares por parte de algunos de los magistrados.

\section{EL PERIODO 2014}

\section{PROCESOS CONSTITUCIONALES DE TUTELA DE DERECHOS}

Sobre la prevalencia de las sentencias emitidas por la jurisdicción ordinaria sobre las resoluciones judiciales que conceden una medida cautelar (Exp. 0978-2012-PA/TC. Caso Westher Leoncio Sotomayor Castañeda)

Mediante sentencia publicada el 24 de enero de 2014, el Tribunal Constitucional se pronunciaría sobre el proceso de amparo interpuesto por Westher Leoncio Sotomayor Castañeda contra la Segunda Sala Civil de la Corte Superior de Justicia de Cusco, y mediante el cual se solicitaba dejar sin efecto la resolución del 14 de diciembre de 2009 que, en segunda instancia, había declarado improcedente el pedido de suspensión de medida cautelar otorgada a favor de Adam Louis Weintraub, dejando subsistentes los efectos de la resolución de primera instancia que inicialmente había estimado su pedido de suspensión de medida cautelar. De acuerdo con lo señalado por el recurrente, la denegatoria de su pedido, que suponía privilegiar una decisión cautelar sobre una sentencia definitiva, implicaba una vulneración de su derecho al debido proceso en su manifestación de eficacia de lo decidido.

Aunque el Colegiado declararía infundada la demanda interpuesta tras considerar que en el caso concreto no se había acreditado la vulneración de derecho constitucional alguno, lo fundamental de este pronunciamiento $\mathrm{y}$, que incluso, se ha elevado a la categoría de doctrina constitucional vinculante 
para todos los jueces y tribunales del país, ha sido el establecer que las medidas cautelares no pueden ser utilizadas con la simple intención de prolongar en el tiempo la ejecución de una sentencia ordinaria o de resistirse a su efectivo cumplimiento, ya que tal proceder podría ocasionar perjuicios irreparables sobre el vencedor del proceso ordinario así como sobre su derecho a la efectividad de las resoluciones judiciales, concluyendo, por consiguiente, que en los casos en los que dicha situación se configure deberá asumirse que el principio pro homine se trasladara inclusive al ámbito de los procesos ordinarios, de manera tal que cuando existan oposiciones o contradicciones en los términos de dichos actos procesales, los jueces del proceso cautelar ordinario deberán optar por hacer prevalecer la sentencia ordinaria sobre cualquier intento de desconocerla o perturbarla a través de la concesión de una medida cautelar ordinaria, habida cuenta que en este tipo de casos específicos la tutela procesal efectiva, manifestada a través de una medida cautelar, viene ciertamente limitada por el derecho a la cosa juzgada.

Sobre la constitucionalidad del régimen carcelario vigente para los condenados por delito de terrorismo (Exp. 1711-2014-HC/TC. Caso Víctor Polay Campos y otros)

El 9 de abril de 2014, el Tribunal Constitucional se pronunciaría sobre el recurso de agravio especial interpuesto por el procurador público del Instituto Nacional Penitenciario (INPE) contra la sentencia de la Quinta Sala Penal para Procesos con Reos Libres de la Corte Superior de Justicia de Lima el 17 de enero de 2014, mediante la cual se había declarado fundada la demanda de habeas corpus promovida por los internos del Centro de Reclusión de la Base Naval (CEREC), señores Víctor Polay Campos, Peter Cárdenas Schulte, Óscar Ramírez Durand y Miguel Rincón Rincón contra el presidente del INPE tras considerar que se habrían vulnerado sus derechos fundamentales aplicables en el ámbito de las condiciones carcelarias.

Como se conoce, una sentencia estimatoria de un proceso constitucional de tutela de derechos (habeas corpus, habeas data, amparo, cumplimiento) emitida a nivel de segunda instancia judicial, resulta en principio definitiva; sin embargo, la jurisprudencia de nuestro Colegiado habilitó hace algunos años la procedencia del recurso de agravio especial en defensa del orden constitucional mediante ejecutoria recaída en el Exp. 2663-2009-PHC/TC (caso Edwin Walter Martínez Moreno) $)^{3}$, y de acuerdo con la cual se hace posible promover este medio impugnatorio en los casos en los que mediante una

3 Sáenz Dávalos (2011: 692-693). 
sentencia constitucional estimatoria y de segundo grado se trasgreda el orden constitucional.

Lo novedoso del presente caso es que aunque en aquella ejecutoria pasada, el Tribunal Constitucional asumió que el orden constitucional al que se refería solo involucraba lo dispuesto en el art. 8 de la Constitución (referido al combate y represión del delito de tráfico ilícito de drogas y, por extensión, al delito de lavado de activos), en la presente decisión se opta por extender dicho enfoque y ahora también se asume que el mismo abarca los casos vinculados al delito de terrorismo, justificándose dicho proceder en la importancia que para el mantenimiento del régimen constitucional y democrático implica el combate contra dicha clase de ilícito. De ahí que para el Tribunal, la sentencia de este nuevo caso sería un complemento de la establecida en el antes citado Exp. 2663-2009-PHC/TC.

Debe en todo caso puntualizarse que, probablemente, el motivo real de este cambio jurisprudencial se haya visto evidenciado en la fuerte polémica que por aquellos días se había generado a raíz de la sentencia emitida por la Quinta Sala Penal para Procesos con Reos Libres de la Corte Superior de Justicia de Lima y que se había decantado por acoger el pedido de un grupo de conocidos cabecillas del grupo terrorista Movimiento Revolucionario Túpac Amaru respecto a su régimen carcelario.

Asumido el conocimiento de la causa por parte del Tribunal, este último consideraría que, en cuanto a la petición de los demandantes porque se les aplique un régimen penitenciario distinto al que al que venían teniendo desde hacía doce años atrás, no existía tratamiento inconstitucional, pues los beneficios penitenciarios a título específico no son derechos fundamentales, mientras que la progresividad en el tratamiento, si bien constituye un mecanismo que el legislador ha considerado conveniente para lograr la finalidad resocializadora, en modo alguno puede entenderse como la única forma de ejecución de un mandato constitucional.

Asimismo, y en lo que respecta a la petición por que se modifique el régimen de visitas vigente en el CEREC, y que a entender de los demandantes resultaba arbitrario, el Tribunal discreparía de dicha alegación, por considerar que el mismo resultaba razonable en atención a la condición de reos cabecillas que tenían los recurrentes del citado centro penitenciario.

La demanda de habeas corpus, en resumen, se declararía infundada. Solo se estimaría como favorable el extremo relativo a la violación del derecho a la educación de los internos, ordenándose al respecto que el Poder Ejecutivo, en el marco de sus competencias, modifique el reglamento del CEREC para que se contemple la posibilidad de que los internos puedan estudiar dentro del mismo. 
Sobre exoneración de deuda tributaria a empresa de televisión comercial (Exp. 04617-2012-PA/TC. Caso Panamericana Televisión S. A.)

Decisión que generaría una gran controversia, sería la publicada el 11 de abril de 2014 en el marco del proceso de amparo interpuesto por la empresa Panamericana Televisión S. A. contra la Superintendencia Nacional de Administración Tributaria (SUNAT), mediante la cual se declara fundada la demanda y a su vez se dispone la inexigibilidad a la actora de la deuda tributaria generada entre el 24 de febrero de 2003 y el 8 de junio de 2009.

Consideraría el Colegiado en este caso que la deuda que mantenía la recurrente con la SUNAT y que comprendía desde el año 2003 hasta el 2009, no resultaba exigible a la nueva administración de la empresa, pues la demandada también resultaba responsable al no haber realizado los cobros de los tributos durante el periodo recurrido materia de la demanda, pese a contar con todas las herramientas necesarias para hacerlo. Puntualizaría el Tribunal que, aunque la deuda se pudo haber cobrado con la administración anterior que había tenido la empresa, la SUNAT no lo hizo en su debido momento, generando con ello una exponencial deuda tributaria para la actual administración que no solo afecta su derecho a la propiedad, sino que resulta totalmente irracional.

Esta sentencia, como antes se indicó, generaría una ola de críticas, no solo debido al componente económico que involucraba la exoneración decretada, sino, y fundamentalmente, debido a que lo resuelto por el Tribunal Constitucional era visto como un abierto trato preferencial para una empresa comercial radicalmente distinto del que por lo general recibía cualquier contribuyente.

La historia de este caso no terminaría, sin embargo y como veremos más adelante, con esta ejecutoria.

\section{Sobre el cambio de precedente constitucional vinculante en torno al control difuso en sede administrativa (Exp. 04293-2012-PA/TC. Caso Consorcio Requena)}

El 14 de abril de 2014, el Tribunal Constitucional emitiría sentencia en el proceso de amparo promovido en este caso por el Consorcio Requena contra la Primera Sala del Tribunal de Contrataciones del Organismo Supervisor de las Contrataciones del Estado (OSCE) y el procurador público a cargo de sus asuntos judiciales. Este proceso tendría por objeto cuestionar la Resolución 170-2012-TC-S1, del 15 de febrero de 2012, por considerar que la misma resultaba contraria a sus derechos a la propiedad, a la tutela procesal efectiva, al debido proceso, a la motivación, a la igualdad ante la ley, a con- 
tratar con fines lícitos, y a los principios de razonabilidad, proporcionalidad y congruencia procesal.

Con independencia de que la citada sentencia haya declarado fundada en parte la demanda específicamente en lo que concierne al derecho a la igualdad, lo verdaderamente incidente de la misma terminó siendo la decisión del Colegiado de dejar sin efecto o revocar el precedente vinculante que en su día había establecido un anterior Pleno del mismo Tribunal Constitucional mediante la sentencia recaída en el Exp. 3741-2004-PA/TC (Caso Ramon Salazar Yarlenque $)^{4}$ que, según se recuerda, autorizaba a todo tribunal u órgano colegiado de la Administración Pública a inaplicar una disposición infraconstitucional cuando considere que ella vulnera manifiestamente la Constitución, sea por la forma o por el fondo, es decir, aplicar el control difuso en sede administrativa.

El Tribunal justifica su decisión revocatoria por entender que el precedente en su dì incorporado desnaturalizaba una competencia otorgada por la Constitución al haber extendido su ejercicio a quienes no estaban inmersos en la función jurisdiccional (en este caso, los tribunales administrativos), careciendo de competencia para ejercer el control difuso de constitucionalidad.

La sentencia, sin embargo, deja en claro que la decisión adoptada no significa ni debe interpretarse tampoco como exclusión alguna en torno de la obligacion que tienen las entidades y organos de la administración pública de garantizar la Constitución, resaltando en todo caso el absoluto sometimiento de la administración pública a la Constitución, o lo que es lo mismo, el mandato de respetar durante la tramitación de los procedimientos administrativos todos los derechos fundamentales asì los principios constitucionales que los garantizan (legalidad, razonabilidad, proporcionalidad, interdicción de la arbitrariedad, etc.).

Un detalle especial que vale la pena puntualizar, es que con independencia de las razones materiales utilizadas por el Tribunal para dejar sin efecto el precedente establecido en el Exp. 3741-2004-PA/TC, se vuelve a insistir desde la perspectiva formal en un argumento bastante opinable como en su día también se hizo para dejar sin efecto vía el Exp. 03908-2007-PA/TC (Caso Proyecto Especial de Infraestructura de Transporte Nacional Provías Nacional) ${ }^{5}$ el precedente vinculante establecido en el Exp. 04853-2004-PA/ TC (Caso Dirección Regional de Pesquería de la Libertad) ${ }^{6}$. Según este argumento, la creaciòn de un precedente no habría seguido las pautas formales de

\footnotetext{
4 Cfr. sentencia publicada el 11-10-2006.

5 Sáenz Dávalos (2010: 641-642).

6 Cfr. sentencia publicada el 22-05-2007.
} 
la jurisprudencia del propio Tribunal (los supuestos para generar un precedente). El hecho es que si este estandar de razonamiento se lo aplicaramos estrictu sensu a todos los precedentes creados por Plenos constitucionales anteriores, simplemente dejarían de existir o tendrían que revocarse la mayor parte del precedentes generados por el propio Tribunal Constitucional.

\section{Sobre el ingreso a los centros comerciales de personas invidentes en compañía de sus perros guía (Exp. 2437-2013-PA/TC. Caso Jane Margarita Cosar Camacho $y$ otros)}

Ejecutoria particularmente importante y aleccionadora, sería publicada el 30 de abril de 2014, como consecuencia del proceso de amparo promovido por Margarita Cósar Camacho, Marcos Antonio Segura Lozano y Juan Pérez Salas contra la empresa Supermercados Peruanos S. A. Plaza Vea.

Lo que se solicitaba vía el proceso planteado era básicamente que, en atención a la condición de invidencia que padecían los recurrentes, se les permitiese el ingreso a los locales comerciales pertenecientes a todas sus cadenas de tiendas en compañía de un animal de asistencia, es decir, de sus perro guía, solicitud que, sin embargo y de manera reiterada, se les venía negando y que a su entender vulneraba sus derechos al libre desarrollo y bienestar, a la libertad de tránsito, a un ambiente equilibrado y adecuado al desarrollo de su vida, a la igualdad y no discriminación, y a la accesibilidad y movilidad personal conforme a los arts. 9 y 20 de la Convención sobre los Derechos de las Personas con Discapacidad, ratificada por el Estado peruano mediante la Resolución Legislativa 29127.

El Tribunal estimaría favorablemente la demanda a través de una fundamentada decisión de acuerdo con la cual se determinaría que la demandada permita que las personas con discapacidad visual ingresen en sus instalaciones acompañados de sus perros guía, garantizando su permanencia en tales locales de manera ilimitada, constante y sin trabas. El razonamiento central que invocaría el Colegiado se sustentaría en la utilidad decisiva que tienen estos animales al permitir a las personas con discapacidad visual el gozar de una plena movilidad personal e interactuar con la mayor independencia posible, colaborando de esta forma en el ejercicio de su derecho a gozar de un ambiente adecuado para el desarrollo de su vida. Estimaría que la prohibición absoluta en la asistencia a las personas con discapacidad visual a través de perros guías que sistemáticamente venía practicando la demandada, resultaba inconstitucional al afectar los derechos a la igualdad, al libre desarrollo y al ambiente adecuado, siendo por lo demás una medida desproporcionada, así se invocaran, como en efecto se había hecho, razones de sanidad. 
Sobre petición de cambio de sexo y el derecho a la identidad (Exp. 0139-2013PA/TC. Caso P. E. M. M.)

Una de las sentencias más opinables que expediría el Pleno constitucional anterior, sería publicada el 5 de mayo del 2014, en el curso del proceso de amparo interpuesto por Rafael Alonso Ynga Zevallos, en representación de P. E. M. M. contra el Registro Nacional de Identificación y Estado Civil (RENIEC) y el Ministerio Público. Su adopción se daría en mayoría (con los votos de los magistrados Urviola Hani, Vergara Gotelli, Calle Hayen y Álvarez Miranda), pues un extenso y fundamentado voto singular emitido por dos magistrados constitucionales dejaría en claro que la misma suponía un pronunciamiento abierto a la polémica desde diversos puntos de vista.

Lo que se peticionaba mediante el citado proceso era, en concreto, el cambio de sexo tanto en el documento nacional de identidad como en la partida de nacimiento perteneciente a P. E. M. M., asumiendo que la identidad que hasta ese entonces mantenía dentro del sexo masculino, debía pasar a considerarse como del sexo femenino. Alegaba el recurrente que al haberse negado dicho pedido a nivel de las entidades administrativas correspondientes se había vulnerado el derecho fundamental a la identidad de la favorecida.

La respuesta de la sentencia sería totalmente desestimatoria sintetizando el raciocinio utilizado básicamente en dos extremos.

Desde una primera perspectiva, se considera que no es viable el cambio de sexo en el registro civil ya que, si bien el P. E. M. M. se presenta como un transexual, dicha condición sería en el fondo una patología que no implica cambio de sexo, habida cuenta que no existe evidencia científica y actualizada que demuestre que el sexo entendido desde una óptica psicológica — que es lo que en el fondo se alegaba- pueda prevalecer sobre el sexo biológico o cromosómico.

El otro razonamiento de la sentencia se esboza a modo de advertencia. De acuerdo con el mismo, alega la mayoría del Colegiado que si se permite el cambio de sexo en el registro civil de una persona de condición transexual, no habría obstáculo para el matrimonio homosexual, planteándose asimismo el problema de la adopción de menores por parte de tales personas. Amparar por otra parte el pedido del recurrente, implicaría una serie de consecuencias adicionales, sean estas aplicables al caso de P. E. M. M. o de otras personas que quieran acogerse a lo resuelto en este caso, invadiéndose de este modo competencias que son propias del legislador ordinario.

Conforme ya se ha consignado, esta toma de posición sería abiertamente rechazada en un extenso y contundente voto singular emitido por los magistrados Eto Cruz y Mesía Ramírez, para quienes el raciocinio de la mayoría se sustentaría en tres argumentos totalmente erróneos. Uno primero de tipo 
autoritativo, basado en la propia posición del Tribunal para la cual, supuestamente, solo hay una forma de verificar lo que es el sexo y esa forma se basa en lo que el mismo Tribunal entiende por el tema; un segundo argumento de tipo científico para el que la identificación de una persona con el sexo opuesto constituye en el fondo una patología psicológica; y un tercer argumento de carácter consecuencialista, de acuerdo con el cual, de fallar el Colegiado en forma estimatoria, se originaría una serie de consecuencias, como las de reivindicar derechos al matrimonio entre personas del mismo sexo, peticiones de adopción entre parejas del mismo sexo, etc.

El voto en minoría refutaría estos extremos, haciendo hincapié en que la posición del Tribunal no solo no tomaría en cuenta lo desarrollado por su propia jurisprudencia, sino que desconocería abiertamente los aportes y definiciones que sobre el mismo tema se han venido dando en el ámbito del derecho internacional de los derechos humanos. Tampoco asumiría la sentencia que la postura de entender a la transexualidad como una anomalía psicológica viene siendo rebatida por la misma comunidad científica, para la que, incluso, catalogar una anomalía o anormalidad como tal requiere de ciertas condiciones sobre las que la sentencia en ningún momento se llega a pronunciar. Por lo demás, la advertencia de que pueda darse paso a otros tipos de reclamo carece del más elemental de los sentidos, pues el demandante en ningún momento ha planteado discusiones alrededor de tales supuestos. En suma y por lo dicho, la posición minoritaria sí se decantaría a favor de la pretensión planteada tras entender que la negativa por parte de las autoridades administrativas de reconocer la procedencia en el cambio de sexo implicaba una abierta vulneración del derecho a la identidad lo que supone que la demanda tendría que declararse fundada.

Tras esta división de posiciones y más allá de lo opinables que puedan resultar en uno u otro sentido, lo lógico era esperar un fallo para el reclamo en concreto. Por lo demás, ello es lo que podría suponerse si nos atenemos a lo señalado en el fundamento 29 de la sentencia en el que el propio Tribunal reconoce que, acorde con su jurisprudencia, no es aconsejable establecer posturas vinculantes en casos altamente conflictivos. Sin embargo, lo más controvertible vendría después, cuando en la parte resolutiva de esta misma ejecutoria y luego de resolverse apelando al tipo de argumentos como los aquí expuestos, la mayoría del Tribunal opta por declarar con carácter vinculante para todos los jueces y tribunales del país (art. VI del Título Preliminar del Código Procesal Constitucional), lo establecido en la presente sentencia.

Polémico proceder, pues este último mandato no solo resulta virtualmente contrapuesto a lo que el Colegiado advirtió en el antes citado fundamento 29, sino que lo que es más delicado, resulta abiertamente contrario a posturas jurisprudenciales perfectamente conocidas y desarrolladas por la 
Corte Interamericana de Derechos Humanos y en las que se deja claramente establecido que se encuentra proscrita todo tipo de discriminación sustentada en motivos de orientación sexual o de identidad de género (cfr. Caso Atala Riffo y Niñas contra Chile).

En nuestro concepto, queda claro que el citado mandato de eficacia vinculante resulta a todas luces inviable y por demás impracticable si tomamos en cuenta lo dispuesto en el art. V del Título Preliminar del Código Procesal Constitucional, que como todos sabemos, obliga a interpretar los derechos fundamentales de conformidad con lo dispuesto en los tratados de derechos humanos y en la jurisprudencia establecida por los organismos internacionales que conocen de dicho tipo de reclamos.

Sobre el interés superior del niño y del adolescente (Exp. 4058-2012-PA/TC. Caso Silvia Patricia López Falcón)

Mediante sentencia publicada el 9 de mayo de 2014, el Tribunal Constitucional se pronunciaría en el proceso de amparo interpuesto por Silvia Patricia López Falcón contra la juez de familia de la provincia de Barranca, proceso en el que se venía cuestionada la resolución judicial que declaró la conclusión y archivo definitivo del proceso de alimentos que la misma amparista había iniciado contra Elvis Andy Zúñiga Ríos, en representación de su menor hija S. M. Z. L.

El argumento sustentatorio de la demandante para considerar arbitraria la resolución judicial cuestionada radicaba en el hecho de que la magistrada emplazada en ningún momento consideró el estado de salud de su hija debidamente acreditado y de que solo por el hecho de haber llegado con dos minutos de retraso a la audiencia programada, haya dado por terminado el proceso en aplicación estricta del Código Procesal Civil, cuando por la naturaleza de los bienes involucrados, debió estarse a lo previsto por el Código de los Niños y Adolescentes.

El Colegiado, muy al margen de que en el presente caso se haya configurado la sustracción de materia justiciable por encontrarse el proceso de alimentos en etapa de ejecución, establecería como doctrina jurisprudencial vinculante y de conformidad con la previsión contenida en el art. VI del Título Preliminar del Código Procesal Constitucional, que el principio constitucional de protección del interés superior del niño, niña y adolescente presupone que los derechos fundamentales reconocidos sobre aquellos $y$, en última instancia, su dignidad, tienen fuerza normativa superior no solo en el momento de la producción de normas, sino también en el momento de su interpretación, por lo que en las diligencias judiciales se impone una actuación tuitiva por parte de los operadores jurisdiccionales, a quienes corresponde la 
adecuación y flexibilización de las normas así como la interpretación que de ellas se realice, a fin de lograr la aplicación más favorable para dar solución a la controversia reclamada, siendo de especial importancia este principio toda vez que se trata de niños, niñas y adolescentes, que tienen especial cuidado y prelación de sus intereses frente al Estado.

Bajo esta misma premisa, se dará por sentado que en los procesos de alimentos, la norma directamente aplicable es el Código de los Niños y Adolescentes y solo en forma supletoria el Código Procesal Civil.

Sobre nulidad de actuados procesales que en vía de ejecución desnaturalizaron una sentencia constitucional del Tribunal Constitucional (Exp. 0791-2014-PA/ TC. Caso Mateo Grimaldo Castañeda Segovia)

Una de las primeras decisiones adoptada por la nueva conformación del Tribunal Constitucional sería la publicada el 15 de julio de 2014, en relación con una serie de pedidos de nulidad formulados tanto por el procurador público del Consejo Nacional de la Magistratura como por el procurador público a cargo de la defensa jurídica del Ministerio Público, los mismos que estarían dirigidos contra la decisión del Tribunal Constitucional del 8 de mayo de 2014, expedida en vía de ejecución de sentencia y mientras contaba con su anterior conformación.

El pronunciamiento que se venía cuestionando tenía como antecedente directo la ejecutoria emitida el 9 de septiembre de 2013 y publicada el 27 de septiembre de 2013, en el marco del Exp. 1044-2013-PA/TC7, la misma que en su momento se había pronunciado declarando fundado un recurso de apelación por salto a favor del cumplimiento de una sentencia constitucional promovido también por Mateo Castañeda Segovia.

Como habíamos comentado en una anterior oportunidad, la ejecutoria dada a conocer el 27 de septiembre de 2013, había desatado rotundas críticas por parte de diversos sectores en el entendido que comportaba una abierta invasión de las competencias pertenecientes al Consejo Nacional de la Magistratura, pues lo que pretendía el Tribunal Constitucional no se limitaba simplemente a tutelar derechos enmendando lo que dicho órgano constitucional hubiese hecho mal, sino que pretendía ordenarle directamente el nombramiento de un nuevo fiscal supremo, debiéndose optar entre el recurrente Mateo Castañeda Segovia o el otro postulante, Cesar Hinostroza Pariachi, no obstante que dicha atribución resultaba exclusiva y excluyente del Consejo.

7 Un breve comentario de esta anterior ejecutoria lo tenemos en Sáenz Dávalos (2014: 630-631). 
El caso es que así como dicha resolución fue emitida por aquellos días, otras posteriores con similares alcances también lo fueron a posterioridad, entre ellas, la del 8 de mayo de 2014. Contra ello se promoverían los ya citados pedidos de nulidad.

Lo que en rigor analizaría el nuevo Pleno era si resultaba constitucionalmente posible anular decisiones del propio Tribunal Constitucional al margen de que las mismas hayan sido expedidas por una anterior conformación, lo que en cierta forma se complicaba un poco si se tomaba en cuenta que el pronunciamiento el 9 de septiembre, que era en realidad el principal de todos los expedidos en vía de ejecución, llevaba formalmente el membrete de una sentencia.

El Colegiado asumiría varias cosas en el presente caso. La primera de todas es que más allá de los nombres utilizados durante las diversas etapas que había venido teniendo el proceso de amparo y sus antecedentes (los que como se ha visto se remontaban al Exp. 1044-2013-PA/TC e incluso al Exp. 049442011-PA/TC), la única e indiscutible sentencia era la originalmente expedida el 16 de enero de 2012, y publicada el 3 de febrero de 2012, mediante la cual el Tribunal Constitucional había declarado fundada la demanda de amparo de Mateo Castañeda Segovia contra el Consejo Nacional de la Magistratura, ordenando que dicho órgano emplazado emita una nueva decisión motivándola en forma debida tras haberse constatado vulneración en los derechos al debido proceso y a la motivación en perjuicio del citado demandante. Lo que vino posteriormente fueron diversos reclamos por supuestos actos de incumplimiento de dicha sentencia primigenia, que dieron lugar a la ya referida ejecutoria de 9 de septiembre de 2013, publicada el 27 de septiembre de 2013, la que, a pesar de haberse denominado como sentencia, no era en estricto un pronunciamiento con dicha características, sino una resolución o auto en vía de ejecución.

Este detalle sería de enorme importancia, pues el Código Procesal Constitucional no permitía la nulidad contra sentencias del propio Tribunal Constitucional conforme a lo previsto en su art. 121, pero en cambio sí habilitaba, según la previsión contenida en el tercer párrafo de dicha norma, el recurso de reposición contra sus autos y decretos legitimando su eventual revocatoria o la propia nulidad de los actuados en torno de los mismos.

Precisamente sería dicho argumento el que finalmente acogería el Tribunal Constitucional para señalar, entre otras cosas, que el proceso había devenido en nulo desde la propia decisión del 9 de septiembre de 2013, que en la práctica, y lejos de haber garantizado el cumplimiento en sus propios términos de la sentencia de 16 de enero de 2012, la había terminado desnaturalizando al ordenarle al Consejo Nacional de la Magistratura algo que en ningún momento aparecía de dicha sentencia. Bajo dicha premisa y habién- 
dose declarado la nulidad desde mucho antes de la resolución de 8 de mayo de 2014, se hacía innecesario pronunciarse en específico sobre la misma. Se dejaría en claro, por lo demás, que la sentencia constitucional primigenia ya había sido cumplida en tanto que el Consejo Nacional de la Magistratura en su día ya se había pronunciado mediante nueva motivación acerca del reclamo de Mateo Castañeda Segovia ${ }^{8}$.

Sobre la creación de la llamada sentencia interlocutoria denegatoria (Exp. 0987-2014-PA/TC. Caso Francisca Lilia Vásquez Romero)

Ejecutoria que marcaría el signo distintivo de la política jurisdiccional a emprenderse por el nuevo Pleno jurisdiccional es, sin duda, la presente, publicada el 26 de agosto de 2014 dentro del proceso de amparo interpuesto por Francisca Lilia Vásquez Romero contra la Segunda Sala Civil de la Corte Superior de Justicia del Santa, la Sala de Derecho Constitucional y Social Permanente de la Corte Suprema de Justicia de la República, así como contra el presidente y el procurador del Poder Judicial.

El tema en debate, no pasaría de un asunto de mero trámite bastante frecuente, pues lo que se cuestionaba como presuntamente irregular era un proceso judicial de tercería preferente de pago, reclamo que por lo demás se terminaría desestimando rápidamente tras constatarse la legitimidad en las actuaciones judiciales cuestionadas.

Lo que, por el contrario, marcaría protagonismo en este caso, sería en concreto el precedente constitucional vinculante que en él se establecería y que, digámoslo de verdad, originaría toda una discusión en torno al rol garantista del Tribunal Constitucional, discusión, a nuestro entender, hasta ahora no cerrada.

En concreto, se optó por instituir como nueva figura la llamada «sentencia interlocutoria denegatoria» (SID), instrumento con el cual el Tribunal se tomaría la prerrogativa de rechazar en adelante, prácticamente de plano y sin audiencia alguna, todo recurso de agravio constitucional que involucre demandas de habeas corpus, amparo, habeas data y cumplimiento, manifiestamente improcedentes o simplemente casos que en esencia se consideren totalmente irrelevantes.

8 Un caso muy similar al que aquí se comenta se presentaría en el Exp. 0776-2014-PA/ TC (Caso César Hinostroza Pariachi), cuya resolución sería publicada el 13-10-2014, dando lugar, igualmente, a la declaratoria de nulidad de los actuados tras considerar que la sentencia constitucional primigenia ya había sido cumplida. 
De esta forma, se asumiría que el uso de la SID se encontraría justificada en cualquiera de cuatro supuestos; a saber: 1) cuando carezca de fundamentación, la supuesta vulneración invocada; 2) cuando la cuestión de derecho contenida en el recurso no sea de especial trascendencia constitucional; 3) cuando la cuestión de derecho contradiga un precedente constitucional vinculante, y 4) cuando se haya decidido de manera desestimatoria en casos sustancialmente iguales.

Aunque esta toma de posición ha sido defendida por algunos sectores académicos, también ha sido criticada muy severamente por otros, en el entendido de que comporta una voluntad auto restrictiva no autorizada ni por la Constitución ni por el Código Procesal Constitucional, lo que en efecto parece evidenciarse si tomamos en cuenta que es la propia norma fundamental la que establece, sin limitación alguna, que el Tribunal Constitucional conoce de toda resolución denegatoria derivada de procesos de tutela de derechos siempre que sea el perjudicado el que así lo decida (art. 202, inciso 2), a lo que debe agregarse que conforme lo dispuesto por Código Procesal Constitucional, el recurso de agravio constitucional solo impone como únicos requisitos para su otorgamiento por parte del Poder Judicial, el carácter desestimatorio del fallo y su interposición dentro del plazo de 10 días (art. 18), en contraposición a lo previsto en el comentado precedente que busca crear un segundo filtro para el citado medio impugnatorio, a cargo del propio Tribunal Constitucional, filtro que sin embargo opera a puertas cerradas y sin ningún tipo de audiencia o mecanismo de defensa, con lo cual se estaría anteponiendo objetivos de productividad por encima de los clásicos roles tutelares que siempre caracterizaron a dicho órgano constitucional.

Cuestión aparte y que no deja de ser igualmente opinable, son los propios supuestos en los que se coloca el Colegiado para legitimar el uso de la SID.

En efecto, la carencia de fundamentación en torno a la vulneración invocada, no parece tomar en cuenta que nuestro proceso de tutela es por esencia antiformalista y que, incluso, existen procesos como el habeas corpus y el habeas data donde el patrocinio de letrado no resulta exigible. Preocuparse porque las demandas se encuentren rigurosamente fundamentadas cual si fueran reclamos judiciales típicamente ordinarios, pareciera responder a una voluntad de comodidad, allí donde lo básico debería ser el estudio de los hechos denunciados en el contexto de los derechos cuya protección se reclama.

Otro tanto puede afirmarse de lo que para el precedente supone de especial trascendencia, habida cuenta que esta no se mide por factores prioritariamente objetivos, como la relevancia social del caso, la oportunidad de sentar jurisprudencia o lo que el propio Tribunal discrecionalmente estime por conveniente. Cada caso es un universo y los procesos de tutela son, ante 
todo y por encima de cualquier cosa, prioritariamente subjetivos, esto es, vinculados a lo que cada justiciable reclama como esencial para la satisfacción de sus derechos. Pretender definir dentro de un marco indeterminado y sobre la base de la auctoritas del propio Colegiado lo que es relevante o no, se presta a un inevitable riesgo de desprotección o carencia tutelar.

Invocar, en tercer lugar, la existencia de un precedente constitucional vinculante como única justificación para un rechazo vía SID, es francamente polémico y hasta contradictorio con la lógica del Código Procesal Constitucional (art. VII, del título preliminar), que prevé la posibilidad de un apartamiento por parte del Colegiado en torno de sus propios precedentes. El justiciable podría encontrarse en desacuerdo con una determinada postura jurisprudencial asumida a título de precedente y solicitar su cambio bajo consideraciones perfectamente legítimas. Una causal desestimatoria como la que aquí se menciona, le cerraría por completo dicha posibilidad, como si la lógica fuese que el Tribunal Constitucional es el único que pudiera decidir en qué momento u oportunidad decide plantearse la revisión de su propia jurisprudencia.

A la cuarta causal que enuncia la ejecutoria, le son aplicables los mismos raciocinios de la tercera, pues no porque se presenten casos sustancialmente iguales quiere ello significar que no puedan darse giros jurisprudenciales cuando la naturaleza de los hechos lo justifiquen (supuestos que requieran impostergable tutela urgente, por ejemplo). Cabe agregar que por mucho que los casos se asemejen, no existen contextos de hecho matemáticamente idénticos. La posibilidad de demostrarlo, simplemente se ve cerrada si como, ya lo hemos indicado con anterioridad, ni siquiera se concede el derecho de audiencia.

Quienes han abogado en pro del precedente aquí comentado han destacado su necesaria utilidad frente a un escenario de frecuentes reclamos a todas luces innecesarios, pero, sobre todo, han saludado su emisión bajo la presunción de una mayor productividad en el Colegiado.

Discrepamos, sin embargo, de ambas apreciaciones. Ya hemos adelantado que los objetivos estadísticos de ninguna manera pueden estar por encima de los roles tutelares y el Tribunal Constitucional, quiérase o no, fue creado para cumplir ese rol tutelar en defecto del tradicional y lamentablemente aún presente, escenario de desprotección respecto del Poder Judicial. No es pues un tema de números, sino de roles.

$\mathrm{Y}$ en cuanto a lo primero, no vemos sinceramente la necesidad de haber creado más causales de rechazo, allí donde el Código Procesal Constitucional ya contempló un esquema bastante amplio y detallado (arts. 4, 5, 70, entre otros), incluso mucho más extenso que el contemplado en su día por la antigua y hoy derogada Ley de Habeas Corpus y Amparo, no 23 506, y normas 
conexas. Para la ejecutoria comentada, el mensaje pareciera apuntar hacia una cada vez más progresiva voluntad de desprotección.

Cabe añadir un detalle importante: aunque esta sentencia sería adoptada por unanimidad, curiosamente y con el tiempo, según veremos más adelante, empezaría a ser cuestionada en su aplicación por uno de los magistrados constitucionales (el doctor Blume Fortini), entre otras cosas, por considerar que su puesta en práctica ha ido evidenciando una utilización excesiva en la manera de entender las causales de rechazo.

\section{Sobre presunta discriminación a niño de padres divorciados en un centro educativo de nivel inicial (Exp. 4577-2012-PA/TC. Caso Yicela Angélica Egúsquiza Meza)}

El 29 de octubre de 2014 se publicaría otra de las sentencias emitidas por el nuevo Pleno del Tribunal Constitucional. La misma sería expedida en el marco del proceso de amparo promovido por Yicela Angélica Egúsquiza Meza a favor de su menor hijo, S. A. O. E. contra el colegio San José Obrero Marianistas y la Gerencia Regional de Educación La Libertad (GRELL).

El tema en debate, y según se planteaba en la demanda, se circunscribía a determinar si resultaba constitucionalmente legítimo que un centro educativo pueda exigir como requisito para la matrícula de un menor de cinco años el que sus padres tengan la condición de casados. La recurrente alegaba al respecto, que el centro educativo emplazado le había impedido matricular a su hijo menor en el nivel de educación inicial correspondiente al año 2012, presuntamente por tener la condición de madre soltera, por lo que tal situación vulneraba los derechos de su menor hijo a la educación y a la igualdad.

Aún cuando el Tribunal Constitucional declararía que en el caso planteado se había configurado una típica situación de sustracción de materia, habida cuenta de que al momento de resolverse la causa el menor en cuyo favor se reclamaba ya se encontraba en tercer grado de primaria y cursando estudios en otro centro educativo, de todos modos consideraría necesario pronunciarse sobre el fondo de la controversia a fin de verificar si realmente y en su momento se había producido o no la alegada vulneración de los derechos.

Dentro de la perspectiva descrita, cinco de los magistrados del Tribunal Constitucional (los doctores Urviola Hani, Miranda Canales, Blume Fortini, Sardón de Taboada y Espinosa-Saldaña) asumirían que la demanda resultaba improcedente en lo que respecta a la alegada vulneración del derecho a la educación, ya que el presupuesto para invocar dicho atributo radicaba en su goce efectivo (presente o pasado) y en el caso examinado quedaba claro que ello no había ocurrido en momento alguno, contándose tan solo con un derecho meramente expectaticio condicionado al cumplimiento de ciertos requisitos 
perfectamente razonables. Dos magistrados (los doctores Ramos Núñez y Ledesma Narváez) discreparían de esta postura aunque suscribirían de todos modos la sentencia en atención a la existencia de otra razón desestimatoria.

En lo que se refiere al derecho a no ser discriminado, los siete magistrados constitucionales considerarían que tampoco había quedado acreditado que la razón por la que no fue matriculado el menor haya respondido al hecho de que su madre tenga la condición de soltera, añadiendo que incluso existía evidencia que otros menores con la misma condición del beneficiado si habían sido matriculados o cursaban estudios en el colegio, lo que descartaba por completo que se trate de una política discriminadora asumida por la entidad emplazada. A pesar de ello, cuatro de los siete magistrados constitucionales (los doctores Miranda Canales, Espinosa-Saldaña, Ramos Núñez y Ledesma Narváez) asumirían (con distinto matiz) que de haberse demostrado que el colegio establece como requisito para permitir el acceso o la matrícula de los menores la condición conyugal de los padres, la demanda si hubiera resultado plenamente legítima.

En suma, no es pues que el Tribunal haya sentado una postura que valide la discriminación de los colegios por razones del estado civil de los padres, sino que ha desestimado la presente demanda, en atención a que los hechos alegados no fueron demostrados.

Sobre el uso del polígrafo en los procedimientos laborales (Exp. 0273-2010-PA) TC. Caso Sindicato Unitario de Trabajadores de Electrolima)

Ejecutoria no exenta de discusión, sería publicada el 30 de octubre de 2014 dentro del proceso de amparo interpuesto por el Sindicato Unitario de Trabajadores de Electrolima contra Tecsur S. A. y Andrick Service S. R. L., así como contra el comandante José A. Salazar y el mayor Juan E. Quispe López, pertenecientes a la División de Investigación de la Policía Nacional del Perú.

Se discutía en este caso si resultaba constitucionalmente legítimo el uso del polígrafo o detector de mentiras sobre los trabajadores de Tecsur S. A., Ivan García Calderón, Luis Alberto Jiménez Zavaleta y Saúl Silva Vaca, debiendo considerarse nulas las declaraciones obtenidas mediante el citado procedimiento.

El Colegiado asumiría que aunque la utilización del mecanismo cuestionado comporta ciertamente una restricción de los derechos a la intimidad personal y a la no autoincriminación, ningún derecho fundamental es absoluto y por lo tanto puede estar sometido a determinadas limitaciones, las mismas que en todo caso deben ser razonables y proporcionales, derivándose de las mismas mucho más beneficios o ventajas para el interés general que perjuicios sobre otros bienes en conflicto. 
En el contexto descrito se asumiría como plenamente viable el uso del polígrafo en las relaciones labores cuando exista de por medio una duda razonable sobre la actuación de un trabajador que haya ocasionado un grave perjuicio al empleador o puesto en peligro la existencia de la entidad empleadora, entre otros supuestos constitucionalmente validos. La sentencia por lo demás, establecería que la admisibilidad del examen a través del polígrafo ha de requerir como requisitos: a) que el examinado tenga conocimiento expreso de la decisión y de las razones para la realización de dicho examen, mediando un plazo razonable entre su notificación y su actuación; b) que la naturaleza y el procedimiento del examen, y toda información que resulte útil deba ser previamente explicado a la persona examinada; c) que el examinado cuente con la presencia de un abogado defensor de su elección o, a petición expresa suya, la asistencia de una persona de su confianza, y d) que el examinado obtenga un ejemplar de los resultados del examen, debidamente suscrito por las personas presentes en la evaluación poligráfica.

Aunque la demanda interpuesta sería desestimada por improcedente, el magistrado Ramos Núñez suscribiría un interesante fundamento de voto, en el que además de aclarar que las razones por las que suscribía el fallo desestimatorio diferían completamente de las utilizadas en la sentencia, advertía de que la adopción de un mecanismo como el polígrafo en el marco de los procedimientos laborales representaba un evidente riesgo, pues diversos estudios científicos han demostrado que la veracidad en las respuestas obtenidas vía el citado medio no se puede garantizar de modo absoluto, habida cuenta que los indicadores de medición utilizados se encuentran incapacitados para discriminar reacciones originadas en estados de ansiedad, ánimo o, incluso, fisiológicos de las personas que se someten al examen.

Por nuestra parte, coincidimos con la apreciación de este fundamento de voto y adicionalmente por considerar que una cosa son las investigaciones en lo criminal, donde los derechos admiten una mayor margen de limitación justificada en la posición especial en la que se encuentra el investigado frente al tipo de imputaciones que se le hace, y otra completamente distinta, la posición de un trabajador en el marco de las relaciones laborales en las que se supone rigen principios esencialmente tuitivos.

La sentencia glosada originó una interesante discusión en los predios académicos.

\section{Sobre la posibilidad de declarar la nulidad de una sentencia constitucional (Exp. 04617-2012-PA/TC. Caso Panamericana Televisión)}

Como advertíamos líneas atrás, la ejecutoria emitida en este caso por parte del Tribunal Constitucional había generado profundas críticas en am- 
plios sectores de opinión, habiendo quedado la sensación de que se trataba de un pronunciamiento excesivo por sus alcances y abiertamente condescendiente con una empresa comercial.

No obstante, y a posteriori de emitida la citada sentencia, fueron presentadas por parte del procurador público de la Superintendencia Nacional de Aduanas y de Administración Tributaria (SUNAT) dos solicitudes, una primera de aclaración, que sería conocida por el Pleno anterior y en su momento desestimada con resolución de 16 de mayo de 2014 y publicada el 20 de mayo de 2014, y una segunda de integración, que sería conocida y resuelta por el nuevo Pleno, esta vez mediante resolución de 18 de noviembre de 2014, publicada el 11 de diciembre de 2014.

El caso es que esta última solicitud, en el fondo, más que un pedido porque se integre la resolución el 16 de mayo de 2014, encerraba en sí una abierta petición de nulidad, ni más ni menos que de la sentencia constitucional publicada el 11 de abril de 2014, lo que originaría una amplia discusión acerca de si el Tribunal Constitucional podía o no declarar la nulidad de sus propias sentencias.

Con anterioridad, ya habíamos visto que el nuevo Pleno había sido capaz de declarar la nulidad de actuados procesales, tal y como había sucedido en los Expedientes 0791-2014-PA/TC (caso Mateo Castañeda Segovia) y 07762014-PA/TC (caso César Hinostroza Pariachi); sin embargo, no se trataba en dichos casos de nulidad de sentencia alguna, sino de resoluciones asumidas como típicos autos, lo que permitía que por vía de reposición se optara por la fórmula revocadora contenida en el tercer párrafo del art. 121 del Código Procesal Constitucional. En el presente supuesto las cosas eran distintas, pues por un lado la sentencia constitucional ya había sido emitida con carácter definitivo y, por el otro, era directamente su nulidad lo que por extensión se estaba solicitando.

El Colegiado, tras una radical discrepancia entre sus propios integrantes, optaría por asumir en decisión mayoritaria (suscrita por los magistrados Urviola Hani, Blume Fortini, Ramos Núñez y Sardón de Taboada) que el pedido de nulidad es improcedente habida cuenta que el Código Procesal Constitucional prohíbe en su art. 121 todo tipo de impugnación contra sus sentencias y que, en todo caso, ha de estarse a los principios de cosa juzgada y seguridad jurídica, siendo el Tribunal Constitucional el órgano de cierre en el sistema jurídico peruano.

Los votos de los magistrados Ledesma Narváez y Espinosa-Saldaña se pronunciaron en contrario, asumiendo que sí es posible que el Tribunal Constitucional declare la nulidad de sus propias sentencias, si estas suponen graves irregularidades o violaciones a los derechos fundamentales, no siendo la cosa juzgada un principio absoluto, sino sujeto a límites. 
Desde nuestra perspectiva, y más allá de la parquedad con la que la mayoría del Tribunal opto por desestimar la solicitud de nulidad aquí comentada, somos de la idea de que hizo lo correcto, pues por principio no existe habilitación legal para justificar un pedido como el que se le formulaba, lo que resultaba especialmente grave al tratarse de una eventual restricción a derechos o principios (y la cosa juzgada lo es en doble vertiente).

Con esta aseveración, por cierto, tampoco estamos diciendo que en el futuro no pueda ser viable incorporar un mecanismo de este tipo, tras una eventual reforma legislativa e incluso constitucional, pero ello no puede hacerse de modo discrecional y a la luz de un caso que un Colegiado opte por escoger libremente, pues con una lógica de ese tipo, cualquier futura composición del mismo Tribunal, podría hacer exactamente lo mismo con las decisiones del actual so pretexto de sus propias o particulares convicciones.

Cabe añadir que no existe un solo antecedente en la jurisprudencia de nuestro Tribunal que haya validado como hipótesis una nulidad de sentencias, siendo muy distinta la nulidad de actuados procesales, práctica que sin ser todo lo perfecta del caso, implica otro tipo de presupuestos y también incidencias.

\section{PROCESOS CONSTITUCIONALES ORGÁNICOS}

Sobre la posibilidad de reducir remuneraciones (Exp. 00020-2012-PI/TC. Caso Congresistas de la República)

En las postrimerías del anterior Pleno y el 9 de mayo de 2014 sería publicada la sentencia en el proceso de inconstitucionalidad promovido por el $25 \%$ del número legal de congresistas de la República, representados por Johny Lezcano Ancieta contra el primer párrafo de la primera disposición complementaria, transitoria y final de la Ley de Reforma Magisterial 29 944, tras considerarse que la citada norma resulta inconstitucional por vulnerar los arts. constitucionales 1 y 23 , relativos a la dignidad de la persona y del trabajador; el art. 24, concerniente con el derecho a la remuneración equitativa y suficiente; el art. 15, referido a la obligación del Estado de procurar la promoción permanente de los profesores; los arts. 2.2. y 26.1, relativos a la igualdad y no discriminación; el art. 23, concerniente la prohibición de limitar el ejercicio de los derechos constitucionales, y el art. 26.2, referido a la irrenunciabilidad de los derechos reconocidos por la Constitución y la ley.

El Tribunal Constitucional desestimaría la demanda interpuesta por considerar que la reducción de la remuneración no puede considerarse como una regla, pero sí en cambio como una excepción sustentada en motivos razonables. Por lo demás, ningún derecho es absoluto, siendo plenamente justifi- 
cada su eventual limitación. De esta forma, la reducción remunerativa dentro de la relación laboral respetará el contenido esencial del derecho a la remuneración si se adopta como una medida extraordinaria y coyuntural que opera en contextos especiales y siempre que se practique de modo proporcional, de manera tal que no suponga una disminución significativa de la remuneración o resulte arbitraria.

A juicio del Colegiado existirían dos formas diferenciadas para que la reducción de la remuneración opere. La primera se presenta cuando la misma es consensuada o se realiza de manera voluntaria, existiendo un acuerdo libre, espontáneo, expreso y motivado entre el trabajador y el empleador. La segunda variante, en cambio, se presentará cuando la reducción remunerativa no es consensuada o se realiza a través de una decisión unilateral por parte del empleador, sin aceptación previa del trabajador, circunstancia en la que se exige que dicha decisión se encuentre basada en una causa objetiva y justificada (debidamente motivada) y que tenga como finalidad cumplir, entre otros aspectos, con una necesidad de reorganización del personal o necesidad de cumplimiento de objetivos económicos y financieros.

\section{Sobre la inconstitucionalidad de medida sancionadora por negarse a brindar el servicio militar obligatorio (Exp. 0015-2013-PI/TC. Caso Congresistas de la República)}

Otra de las últimas sentencias emitidas por la anterior conformación de magistrados, fue publicada el 23 de mayo de 2014, en el marco del proceso de inconstitucionalidad interpuesto por el $25 \%$ del número legal de congresistas de la República contra el Decreto Legislativo 1146, modificatorio de diversos arts. de la Ley del Servicio Militar 29 248, por estimar que con la norma impugnada se ha pretendido convertir en obligatorio lo que desde lo previsto por el art. 163 de la Constitución, es simplemente voluntario.

En el presente caso, por lo menos cuatro magistrados del Tribunal Constitucional (los doctores Urviola Hani, Eto Cruz, Mesía Ramirez y Vergara Gotelli) entienden que el llamado servicio militar obligatorio sí se encuentra justificado en el cumplimiento del deber constitucional de colaborar con la defensa nacional en los términos previstos por el art. 163 de la Constitución. Otro magistrado, como Calle Hayen, considera abierto el tema a una regulación que sea la que defina si el servicio militar puede ser obligatorio o voluntario. El magistrado Álvarez Miranda se cuestiona, sin embargo, el desprender una obligatoriedad en el servicio, a partir de lo señalado en el antes citado dispositivo constitucional, siendo este último en rigor el único que se pronuncia por la inconstitucionalidad total del dispositivo invocado. 
A partir de lo señalado, se considera que la demanda resulta infundada en lo que respecta a la inconstitucionalidad del sorteo realizado para cubrir vacantes por llamamiento forzoso. Este último, en otras palabras, será plenamente constitucional.

En lo que, sin embargo, sí estarán todos de acuerdo y por ende se declarara fundada en parte la demanda, es en el hecho de haberse previsto por la norma impugnada una multa del $50 \%$ de una unidad impositiva tributaria (UIT, S/3800) para exceptuarse del servicio militar, ya que tal exigencia, según se afirma, permitiría convalidar un trato diferenciado que discrimina a un grupo determinado de ciudadanos frente a otro en función de su condición estrictamente económica.

Finalmente y en el contexto de lo antes señalado, el Tribunal exhorta al Congreso de la República a fin de que regule un mecanismo alternativo a la suspensión de los efectos del DNI para los infractores del servicio militar obligatorio, puesto que dicha suspensión podría generar una condena de muerte civil, al privarle a una persona de su capacidad de ejercicio de forma indefinida.

Sobre restricciones a la propiedad mediante una de ley de presupuesto (Exp. 00012-2014-PI/TC. Caso Cinco mil ciudadanos)

El 10 de diciembre de 2014 se publicó una interesante sentencia de inconstitucionalidad, esta última a cargo ya del nuevo Pleno. La misma sería consecuencia de la demanda de inconstitucionalidad promovida por más de cinco mil ciudadanos contra el Congreso de la República y mediante la cual se cuestionaría la septuagésima segunda disposición complementaria final de la Ley 30114 de Presupuesto del Sector Público para el año fiscal 2014, tanto por razones de forma como por razones de fondo.

De acuerdo con lo señalado por los demandantes, la norma objeto de cuestionamiento resultaría inconstitucional por razones de forma, habida cuenta de que para su aprobación no se solicitó el dictamen de la Comisión de Presupuesto y Cuenta General de la República o se tramitó exoneración de dicho dictamen, como en todo caso correspondía. En cuanto al fondo, se alegó que la norma impugnada violaba el derecho de propiedad al disponer que la devolución del dinero del fondo nacional de vivienda corresponderá a quienes se hayan inscrito o registrado solo hasta el 31 de agosto de 2014 y al circunscribir la devolución de los aportes únicamente a las contribuciones recaudadas a los trabajadores, mas no así a los aportes realizados por los empleadores, el Estado u otras instituciones.

El Colegiado descartaría por mayoría el argumento de inconstitucionalidad por razones de forma (votarían en dicho sentido los magistrados Ur- 
viola Hani, Miranda Canales, Ramos Núneez, Sardón de Taboada, Ledesma Narváez y Espinosa-Saldaña). Sin embargo, y en cuanto al fondo, optaría por considerar fundado en parte el reclamo, tras asumirse que imponer un plazo respecto del derecho que se tiene a recibir la devolución de los aportes realizados, constituye una restricción abiertamente injustificada del derecho constitucional de propiedad.

Interesante sería la posición esbozada por el magistrado Blume Fortini, vía su voto singular, y que abogaría a favor de la inconstitucionalidad total de la norma impugnada, tanto por razones de forma como de fondo. En cuanto a lo primero, el citado voto dejaría en claro que conforme al art. 105 de la Constitución del Estado, «ningún proyecto de ley puede sancionarse sin haber sido previamente aprobado por la respectiva Comisión dictaminadora [...]» y que en el presente caso, había sido abiertamente omitido dicho procedimiento. En cuanto al fondo, si bien coincidiría con la mayoría en cuando a la inconstitucionalidad material de la norma impugnada al establecer un plazo a los beneficiarios del aporte por fondo nacional de vivienda, dejaría muy claro que el citado fondo no tiene naturaleza tributaria y que lo que resultaría materia de devolución, no solo debía limitarse a los aportes de los trabajadores, sino extenderse a los aportes de los propios empleadores, el Estado y otras instituciones, pues el referido monto involucra un concepto unitario e indivisible al que incluso cabría añadirse los intereses por efectos del tiempo.

\section{EL PERIODO 2015}

Entre las decisiones que han sido emitidas en el presente periodo anual, cabe consignar las siguientes:

\section{PROCESOS CONSTITUCIONALES DE TUTELA DE DERECHOS}

Sobre la no aplicación de las reglas del amparo arbitral a los supuestos de resoluciones emitidas en vía de ejecución de los laudos arbítrales (Exp. 084482013-PA/TC. Caso Procurador Público del Ministerio de Educación)

Pronunciamiento poco conocido, pero creemos que bastante importante, lo constituye el auto publicado el 20 de enero de 2015, mediante el cual el Tribunal Constitucional se pronunciaría en el curso del proceso de amparo promovido por el procurador público del Ministerio de Educación, Octavio Olegario Olivo García contra el Tribunal Arbitral integrado por los señores árbitros Federico Tovar Freyre, Luis Loayza Lazo y Ramón Abásolo Adrianzen, así como contra el ciudadano Jorge Segundo Zegarra Reátegui. 
El tema objeto de reclamo se circunscribía al cuestionamiento de determinadas resoluciones emitidas en la fase de ejecución de un proceso arbitral, es decir, no al cuestionamiento mismo del laudo o pronunciamiento con el que se concluye este tipo de proceso, sino a las incidencias resolutivas del mismo, tras considerar que las mismas vulneraban los derechos a la tutela procesal efectiva, la cosa juzgada, la debida motivación y el derecho de propiedad.

La pregunta clave que correspondía hacerse en este caso, bastante especial, era si al mismo le resultaban aplicables o no las reglas del amparo arbitral establecidas en el precedente recaído en el Exp. 0142-2011-PA/TC (caso Sociedad Minera de Responsabilidad LTDA María Julia9), de acuerdo con las cuales, solo se verificaba la pertinencia de esta modalidad de amparo en tres supuestos muy específicos (vulneración de precedentes del Tribunal Constitucional, uso indebido del control difuso y afectación de derechos de un tercero), optándose por asumir que los reclamos por otro tipo de hipótesis solo podrían ser tramitados en el ámbito del llamado recurso de anulación de laudo en sede judicial.

Aunque el Tribunal Constitucional terminaría desestimando la demanda por improcedente, lo importante es que llegó a la conclusión de que el antes citado precedente y sus reglas no resultarían de ninguna manera aplicables a los casos en los que el agravio proviene de resoluciones arbitrales distintas al laudo arbitral y, en particular, a las emitidas en fase de ejecución de laudo, entendiéndose que en tales casos no existe la posibilidad de promover ningún tipo de mecanismo recursivo que no sea estrictamente el amparo.

El pronunciamiento, como se observa, abre una perspectiva bastante interesante en la que no se puso el Tribunal al momento de crear el precedente antes mencionado y que ratifica que el mismo, como se dijo en su momento, tuvo una vocación bastante restrictiva.

Sobre la inconstitucionalidad de una condena penal en el marco de lo que representa el principio de motivación resolutoria (Exp. 08439-2013-PHC/TC. Caso Constantina Palomino Reinoso)

Una de las pocas oportunidades en las que el nuevo Colegiado ha optado por avocarse de lleno al conocimiento de un proceso constitucional contra resoluciones judiciales se observa en la ejecutoria publicada el 7 de abril de 2015.

9 Cfr. Sáenz Dávalos (2012: 619-621). 
Se trata en rigor de un proceso de habeas corpus promovido por Constantina Palomino Reinoso contra los jueces integrantes de la Sala Mixta Descentralizada de la provincia de la Convención-Quillabamba de la Corte Superior de Justicia del Cusco y los vocales de la Sala Penal Transitoria de la Corte Suprema de Justicia de la República, y en el que se cuestiona las sentencias penales condenatorias de 29 de enero de 2011 y 5 de agosto de 2011, tras considerar que las mismas han vulnerado su derecho constitucional al debido proceso, en particular, el principio de motivación resolutoria.

El origen de todo radica en la imputación que se realiza sobre la accionante respecto de la comisión de un delito de naturaleza muy grave, consistente en haber agredido sexualmente a una menor de edad, motivo por el que se le termina condenando a treinta años de pena privativa de la libertad. Según la recurrente, la condena impuesta por la Sala Superior y posteriormente confirmada por la Corte Suprema, resulta totalmente arbitraria por el tipo de argumentación que utiliza, pues se basa en una deducción ilógica, consistente en dar veracidad a la totalidad de la versión de la menor, esto es, por aceptarla como cierta en todos sus extremos, para luego utilizar de la misma solo la parte que conduce a su incriminación y, en cambio, descartar por completo aquella parte que puede dar lugar a exención de responsabilidad.

El Tribunal Constitucional decidió este caso por mayoría. Cuatro de los siete magistrados (Urviola Hani, Blume Fortini, Ramos Núñez y Sardón de Taboada) optarían por estimar favorablemente la demanda, precisamente por considerar evidentemente desvirtuado uno de los estándares más importantes que impone el principio de motivación resolutoria, como lo es sin duda la exigencia de motivación interna en el razonamiento y que, como lo explica la jurisprudencia del propio Colegiado, se produce cuando en el caso que se juzga existe invalidez entre las inferencias a las que se llega a partir de las premisas de las que se parte. En el caso concreto, si las salas penales demandadas partieron de la aseveración de que todo lo que dijo la menor presuntamente agraviada era cierto, lo lógico era utilizar dicha argumentación en todo lo que pueda deducirse del caso. Sin embargo, lejos de ello, solo se utilizo la parte de la versión que permitía construir una tesis incriminadora, descartando por completo cualquier tipo de razonamiento que utilizando las mismas premisas pretendidamente ciertas condujera a la no incriminación de la demandante.

El voto en minoría (suscrito por los magistrados Ledesma Narváez y Espinosa-Saldaña y al cual se adhiere el magistrado Miranda Canales), opta por circunscribir la controversia a un estricto asunto de competencias, asumiendo que en el presente caso, se pretende convertir al juez constitucional en alguien que reemplace al juez penal, lo que a juicio de los disidentes, no es posible. 
Sobre el equilibrio entre la inviolabilidad de las comunicaciones y la permisión de quien participa en las mismas (Exp. 0867-2011-PA/TC. Caso Alan Siasmany Quintano Saravia)

Sentencia particularmente interesante se daría a conocer el 18 de mayo de 2015 con motivo del proceso de amparo promovido por Alan Siasmany Quintano Saravia contra la fiscal de la Tercera Fiscalía Provincial Penal de Abancay, Mary Luz Merino Villegas, y contra el procurador del Ministerio Público, alegándose al respecto una presunta vulneración de los derechos al secreto y la inviolabilidad de las comunicaciones y la contravención al principio de interdicción de la arbitrariedad.

Se solicitaba en este caso la nulidad e ineficacia de ciertos medios de prueba consistentes en grabaciones sobre las conversaciones que había mantenido el demandante con Tomas Gutiérrez Berrio y que, según afirmaba, se habían realizado sin su libre consentimiento con motivo de la investigación que se le venía siguiendo por presunto delito de cohecho pasivo propio en agravio de la citada persona. Según el recurrente, por más que el presunto agraviado haya aceptado que lo graben, ello no significa que se le perjudique en su condición de interlocutor, ni siquiera a título de las investigaciones seguidas en su contra.

El Colegiado llegaría a la conclusión de que el derecho a la inviolabilidad de las comunicaciones no se ve vulnerado cuando alguna de las partes intervinientes en el proceso comunicativo graba la comunicación en la que forma parte o, cuando de manera libre, voluntaria y expresa, permite, posibilita o autoriza la interceptación, grabación o el acceso al contenido de la comunicación a un tercero ajeno a la comunicación misma.

En el caso concreto, Tomas Gutiérrez Berrio había denunciado a Alan Siasmany Quintano Saravia por venir siendo objeto de presiones indebidas para el pago de una suma de dinero, por lo que se acordó que, a fin de acreditar el delito en el que se venía incurriendo, se procediera a grabar las conversaciones del denunciante con el autor de tales actos. Es en las circunstancias descritas y tras contarse con el consentimiento expreso de una de las partes que participaba en dicha comunicación, que se estimó como adecuada la respectiva intervención en las comunicaciones realizadas, no apreciándose de dicho proceder conducta inconstitucional alguna.

Esta ejecutoria permitiría, pues, abordar el desarrollo de aspectos concernientes con la inviolabilidad de las comunicaciones, que hasta la fecha y no obstante su importancia, no habían sido materia de tratamiento alguno.

La sentencia respectiva sería evacuada por la Segunda Sala del Tribunal Constitucional integrada por los magistrados Blume Fortini, Ramos Núñez y Ledesma Narváez. 
La creación de un nuevo precedente constitucional vinculante en materia de protección de los trabajadores en los casos de desnaturalización de la contratación laboral (Exp. 05057-2013-PA/TC. Caso Rosalía Beatriz Huatuco Huatuco)

Probablemente la sentencia que más debates ha generado hasta la fecha por parte del nuevo Pleno es esta última, publicada el 1 de junio de 2015 en el marco del proceso de amparo promovido por Rosalía Beatriz Huatuco Huatuco contra el Poder Judicial y donde lo que reclamaba la demandante era haber sido objeto de una ruptura de su vinculo laboral, producida como consecuencia de una abierta desnaturalización en su contratación laboral.

Los hechos en apariencia eran muy simples y vistos en la perspectiva de cómo se venían resolviendo hasta ese momento ese tipo de causas, no debieran haber originado otra respuesta que no fuese la estimatoria, con reposición de por medio. Sin embargo, el Tribunal en decisión mayoritaria, optaría por cambiar todas sus líneas jurisprudenciales estableciendo un precedente constitucional que hasta hoy día sigue siendo objeto de profundas discusiones y no más de un cuestionamiento.

Debe recordarse que antes de la emisión del precedente que aquí se comenta, el Tribunal Constitucional venía manejando una frondosa jurisprudencia ratificada en sucesivos Plenos que lo habían venido integrando. Conforme a la misma, la desnaturalización en la contratación laboral pública, no era imputable al trabajador, sino a la propia entidad contratante que, con la finalidad de eludir diversas obligaciones impuestas por la legislación laboral pública, optaba por contrataciones temporales que iba renovando cada cierto tiempo a fin de que quienes se encontraban sujetos a dicho régimen no pudieran acceder a los derechos que correspondían a un trabajador del Estado debidamente nombrado tras un concurso de por medio. En esas circunstancias y cuando un trabajador público era despedido so pretexto de la conclusión en el periodo establecido en su contrato, se justificaba plenamente la reclamación por vía del amparo y la jurisprudencia tras calificar dicho acto como inconstitucional ordenaba la inmediata reposición a la entidad pública emplazada, con lo cual habían dos formas de ser trabajador público: una totalmente ordinaria, que implicaba concurso público y plaza debidamente presupuestada; y otra extraordinaria, producida precisamente por mandato judicial, tras detectarse desnaturalización en la contratación laboral.

Lo que el precedente constitucional ahora establecido vendría a imponer serían en rigor dos reglas, una sustantiva y otra procesal.

La primera regla y, en realidad, la esencial, establecía que, en adelante, los casos de desnaturalización de la contratación laboral producida en el ámbito de la Administración Pública ya no darían lugar a una reposición en el puesto 
de trabajo, sino únicamente indemnización, y que la vía procesal de reclamo ya no sería el amparo, sino la del proceso laboral ordinario. Sustento de dicha postura sería que la desnaturalización en la contratación no puede suponer de ninguna forma que se ingrese a la Administración Pública sin concurso público y sin que exista plaza debidamente presupuestada, con lo cual, por muy errada y abusiva que haya sido la Administración al desnaturalizar los contratos, no se le puede imponer cargas de ninguna especie. En otras palabras, toda la lógica pro trabajador consagrada en la jurisprudencia que por años vino desarrollando el propio Tribunal y que incluso el Poder Judicial había venido recogiendo y desarrollando, pasa a ser sustituida por una lógica contraria, donde el Estado termina inmune y el trabajador ausente de tutela que no sea la estrictamente indemnizatoria.

La otra regla, y que en nuestra opinión resultaría tanto más polémica, es que dicho precedente se aplica incluso a los procesos en trámite, con lo cual, si un trabajador público que había sido objeto de una desnaturalización en su contratación había acudido a reclamar al amparo mucho antes de la emisión del citado precedente, dicho proceso ya no le serviría de nada ni por supuesto obtendría reposición alguna en su puesto de trabajo, sino que su reclamo sería derivado a la vía laboral ordinaria a donde solo pueda reclamar indemnización. En nuestra opinión, esta última postura encierra una abierta vulneración del debido proceso desde la perspectiva de lo que representa el procedimiento preestablecido por la ley, ya que no resulta lógico ni menos por supuesto razonable que un procedimiento sustentado con base en unas reglas predeterminadas por la propia jurisprudencia, se vea alterado a mitad de camino en abierto perjuicio de quien con toda legitimidad optó por promoverlo. Sobre esto último conviene, incluso, anotar un detalle que, aunque formal, no deja de ser especialmente relevante.

De acuerdo con la práctica jurisprudencial del propio Colegiado, la emisión de un precedente constitucional vinculante exige como mínimo el respaldo de cinco magistrados constitucionales, lo que supone que si el mismo no se presenta, simplemente no hay precedente. El caso es que la emisión de la presente ejecutoria, si bien conto con el apoyo mayoritario de cinco magistrados (Urviola Hani, Miranda Canales, Ramos Núñez, Ledesma Narváez y Espinosa-Saldaña) y dos votos en contra (los emitidos por los magistrados Blume Fortini y Sardón de Taboada), la mayoría lograda solo lo fue para la instauración de la regla estrictamente sustantiva, es decir, la que propone un nuevo tratamiento para los supuestos de reclamos por desnaturalización de la contratación laboral, no así para la regla procesal concerniente con la aplicación inmediata de dicho precedente a los procesos judiciales en trámite, pues aunque cuatro de los magistrados efectivamente votaron a favor de la primera regla, el magistrado Ramos Núnez emitió un fundamento de voto en el que 
dejo claramente establecido que estaba de acuerdo con el cambio jurisprudencial, pero de ninguna manera con su aplicación inmediata a los procesos iniciados con anterioridad, lo que a su entender implicaba que el precedente creado solo podía ser aplicado a partir de los procesos tramitados a posteriori de su emisión. Esta misma postura se vería ratificada en la resolución de aclaración publicada por el mismo Colegiado el 9 de julio de 2015.

Siendo las cosas del modo descrito, estaríamos en condiciones de afirmar que el precedente creado solo resultaría obligatorio para los procesos o reclamos iniciados con posterioridad a su dación, pero no así para aquellos reclamos iniciados con anterioridad, los mismos que desde nuestra óptica bien podrían ser resueltos conforme al esquema jurisprudencial anterior (es decir, el que permitía el amparo y además la reposición).

Conviene dejar anotado que la sentencia que aquí se comenta generó dos votos singulares que, aunque fueron esbozados desde percepciones totalmente distintas, dejaron en claro que el modelo perseguido por el nuevo precedente no resultaba adecuado a la luz de lo establecido por la Constitución.

Particular comentario nos merece el del magistrado Blume Fortini, quien advierte los enormes retrocesos que la nueva fórmula implica de cara a la jurisprudencia garantista que siempre caracterizó al Tribunal Constitucional en materia laboral y la arbitrariedad evidente que implica su aplicación inmediata a los procesos en trámite para aquellos justiciables que iniciaron sus reclamos conforme a unas reglas y su evidente desvirtuación a mitad de camino, postura esta última en la que coincide con lo ya señalado por el magistrado Ramos Núñez.

Decíamos al inicio que este precedente es de los que más polémica o debates generó. Incluso no se limitó al ámbito estrictamente académico, sino que traspasaría la barrera jurisdiccional, pues por vez primera y a diferencia de lo que tradicionalmente venía ocurriendo en los predios de la justicia ordinaria, en los que casi siempre se observaba un seguimiento riguroso de los criterios jurisprudenciales del Tribunal Constitucional (sea por vía de su doctrina o de sus precedentes), en esta ocasión muchos jueces empezarían a morigerar los alcances del precedente creado, aplicando sensatamente la técnica del distinguishing, con lo que implícitamente se haría evidente o cada vez más palpable una cierta discrepancia con el camino en adelante impuesto.

\section{Sobre el computo del plazo razonable en la duración de los procesos penales (Exp. 0295-2012-PHC/TC. Caso Aristóteles Roman Arce Paucar)}

El 3 de junio de 2015, sería publicada una sentencia que, al revés de la anteriormente mencionada, sí puede considerarse garantista. Su expedición se daría en el curso del proceso de habeas corpus promovido por Aristóteles 
Román Arce Paucar contra los jueces de la Tercera Sala Penal de la Corte Superior de Justicia del Callao.

Con independencia del reclamo específicamente planteado y que se circunscribía al cuestionamiento de un proceso penal indebidamente dilatado por varios años en claro perjuicio del procesado, lo importante sería el establecimiento de criterios para determinar cómo es que se contabilizan los plazos de inicio y de termino en la duración de un proceso a los efectos de que pueda considerarse razonable.

En el ámbito de nuestra jurisprudencia, justo es reconocer que desde hace ya varios años y gracias a diversas sentencias emitidas por anteriores Plenos del Tribunal Constitucional, ha existido un desarrollo bastante progresista tanto en materia de plazo razonable en la duración de una detención como en materia de plazo razonable en la duración de los procesos, especialmente, por cierto, en los de tipo penal.

Tema que, sin embargo, siempre había originado debates, era el momento exacto en el que se iniciaba el computo correspondiente para determinar la duración de un proceso penal, pues había quienes postulaban que ello solo debía tomar como referencia directa el inicio estricto del proceso con el auto de apertura, mientras que otros afirmaban que debería tomarse en cuenta la etapa investigadora del Ministerio Público. Otros, incluso, creen que debe estimarse la fase estrictamente policial, lo cual no dejaba de tener sentido si se reparaba en la duración de diligencias en cada uno de dichos ámbitos y en las eventuales medidas que en relación con los derechos pudiesen adoptarse o tal vez permitirse.

La importancia de la ejecutoria que aquí se comenta radica en haber establecido a título de doctrina jurisprudencial vinculante criterios delimitativos en torno al inicio y al término del plazo razonable en los procesos penales. De esta forma, se dirá en relación con lo primero que el cómputo del plazo razonable opera desde la apertura de la investigación del delito, la que comprende la investigación policial o la investigación fiscal o el inicio del proceso judicial en los casos de delitos sujetos a la acción privada. Dicho momento inicial, según específica la sentencia, puede coincidir con la detención policial o con otra medida restrictiva de derechos, pero no resulta requisito indispensable para determinar el inicio del cómputo.

En lo que respecta a la finalización o término del proceso, el Tribunal ratificará la idea de que el referente determinante en el cómputo del plazo se configura en el momento en que el órgano jurisdiccional expide la decisión definitiva mediante la cual se resuelve la situación jurídica de la persona inmersa en el proceso.

Sobre la base de estos mismos criterios, el Colegiado resolverá el caso en concreto optando por declarar fundada la demanda, tras constatar una evi- 
dente vulneración en el derecho al plazo razonable en la duración del proceso seguido contra el recurrente.

\section{Sobre la determinación de lo que constituye la vía procedimental igualmente satisfactoria y los casos en los que resulta oportuna la recurrencia al amparo (Exp. 02383-2013-PA/TC. Caso Elgo Rios Núñez)}

Otra ejecutoria que resultaría de especial interés, aparecerió publicada el 9 de julio de 2015 en el marco del proceso de amparo interpuesto por Elgo Rios Núñez contra el Proyecto Especial Pichis Palcazú y en el que se reclamaban supuestas vulneraciones al derecho al trabajo y a la libertad de sindicalización.

Lo importante de esta sentencia no vendría sin embargo por el caso mismo, el cual sería resuelto en forma desestimatoria, sino por el establecimiento de un precedente constitucional vinculante en el que se desarrollarían criterios a efectos de determinar lo que el art. 5, inciso 2 del Código Procesal Constitucional enuncia como "vía procedimental igualmente satisfactoria».

Conviene recordar al respecto que la instauración de un modelo de amparo residual o subsidiario en el esquema procesal constitucional que actualmente tenemos, no suponía, como algunos erróneamente habían entendido, que el amparo no pueda utilizarse porque se tiene a la mano el proceso judicial ordinario. De lo que se trataba era de asumir la exclusión del proceso constitucional, solo y exclusivamente, si en el ámbito de los procesos judiciales ordinarios se ofrecía una tutela equivalente a la que pueda obtenerse en el amparo, con lo cual, la llamada vía procedimental igualmente satisfactoria era siempre un proceso judicial ordinario, pero no todos los procesos judiciales ordinarios eran necesariamente o en todos los casos, vías procedimentales igualmente satisfactorias, dependiendo del tipo de proceso ordinario y de sus características el decidir si prospera o no el amparo.

Durante buena cantidad de tiempo (si contabilizamos que el Código Procesal Constitucional entro en vigencia en diciembre de 2004) se vino dando un desarrollo jurisprudencial del tema bastante casuístico (dependiendo de cada situación), pero sin que ello supusiera establecer líneas de raciocinio más bien generales. Con la emisión del precedente que aquí se comenta, se pretende revertir dicha situación.

Lo que en rigor nos dice la ejecutoria es que para establecer que nos encontramos ante una vía procedimental igualmente satisfactoria, necesariamente se ha de contemplar la existencia de cuatro elementos: a) que la estructura del proceso resulte idónea para la tutela del derecho; b) que la resolución que pueda emitirse pueda brindar tutela adecuada; c) que no exista riesgo de 
irreparabilidad, y d) que no exista necesidad de una tutela urgente, derivada de la relevancia del derecho o de la gravedad de las consecuencias.

Estos cuatro elementos, por lo demás, deben presentarse de manera copulativa (simultánea), lo que supone que el solo hecho de faltar alguno de ellos automáticamente invalidará la calificación del proceso judicial ordinario como vía procedimental igualmente satisfactoria, circunstancia en la que, evidentemente, resultará plenamente procedente la recurrencia al amparo constitucional.

A título personal, entendemos que la fórmula adoptada es no solo la más adecuada, sino que hace buen rato se venía reclamando como necesaria. De paso, nos estaría graficando que en nuestro ordenamiento jurídico el amparo residual o subsidiario no responde a un modelo radical como algunos lo creen, sino más bien a un modelo atenuado.

El precedente establecido contaría con el apoyo de seis de los magistrados: Urviola Hani, Miranda Canales, Blume Fortini, Ramos Núñez, Ledesma Narváez y Espinosa-Saldaña, contando con la oposición del magistrado Sardón de Taboada.

Sobre un recurso de agravio especial contra una sentencia constitucional inconstitucional (Exp. N N 05811-2015-PHC/TC. Caso Nadine Heredia Alarcón)

Sentencia que generaría una gran discusión, principalmente por el contexto mediático e incidencia política que le rodeaba, fue la publicada el 20 de octubre de 2015, como consecuencia de un recurso de agravio especial promovido por el procurador público a cargo de la defensa jurídica del Ministerio Público y el fiscal provincial de la Primera Fiscalía Supraprovincial Corporativa Especializada en Delito de Lavado de Activos y Pérdida de Dominio contra la Sexta Sala Penal para procesos con reos libres de la Corte Superior de Justicia de Lima.

Los hechos tienen por antecedente la investigación fiscal que el Ministerio Público había iniciado contra la entonces primera dama de la nación, Nadine Heredia Alarcón, a instancias de un presunto delito de lavado de activos. La investigación promovida a principios de 2015, era cuestionada por la defensa de Heredia, alegándose que con anterioridad ya había sido investigada exactamente por los mismos hechos y que, por consiguiente, de ninguna manera podía ser objeto de nuevas pesquisas, ya que tal proceder resultaba totalmente arbitrario al vulnerar la regla ne bis in idem y el derecho a la cosa decidida en sede fiscal.

Aunque lo que decía la primera dama era en parte cierto, también lo era que la investigación anterior a la que se refería había sido totalmente deficitaria además de severamente cuestionada por las presiones políticas presuntamente 
ejercidas desde el propio Gobierno para dejarla finalmente sin efecto. A ello se agrega que la nueva investigación, a diferencia de la primigenia, se basaba en nueva evidencia de acuerdo con lo señalado por el Ministerio Público.

El hecho es que Nadine Heredia Alarcón optó por promover un proceso de habeas corpus cuyo petitorio buscaba que se le excluyera tanto a ella como a sus familiares de los alcances de la denuncia y se dispusiera la nulidad de todo tipo de resolución fiscal o judicial vinculados con la misma. En su momento, dicha demanda constitucional sería declarada fundada en parte por el Cuadragésimo Tercer Juzgado Penal de Lima por entender que había sido vulnerado el derecho al debido proceso de la señora Nadine Heredia. Y posteriormente también confirmada por la Sexta Sala Penal para procesos con reos libres de la Corte Superior de Justicia de Lima, instancia que incluso resolvería que tampoco serían investigados sus familiares, lo que terminaría por desatar profundos cuestionamientos en diversos sectores de opinión que vieron en dichos fallos (sobre todo en el de segundo grado) una evidente voluntad favorecimiento y parcialidad hacia la primera dama.

Es ante dicha circunstancia que el procurador público del Ministerio Público y el fiscal provincial de la Primera Fiscalía Supraprovincial Corporativa Especializada en Delito de Lavado de Activos y Pérdida de Dominio plantearían el recurso de agravio especial que aquí se menciona, bajo la lógica de que las sentencias emitidas en dicho proceso constitucional resultaban arbitrarias principalmente por desconocer las competencias del Ministerio Público.

El Tribunal Constitucional, tras asumir la legitimidad del impugnatorio planteado, revocaría las resoluciones emitidas por el Poder Judicial procediendo a declarar infundada la demanda de habeas corpus, tras considerar que no existe violación a los derechos de la demandante ni sobre el resto de investigados. La ejecutoria dejaría en claro que el estatus de inamovilidad de una decisión fiscal de no ha lugar a formalizar una denuncia fiscal solo se adquiere si la respectiva investigación ha cumplido, en términos razonables, con agotar la actividad necesaria para definir la atipicidad del hecho investigado. Y que al revés de ello, resulta constitucionalmente legítimo el ejercicio de facultades de investigación fiscal, pese a un archivo primigenio cuando: a) existan elementos probatorios nuevos no conocidos con anterioridad por parte de la autoridad, y b) cuando se aprecia de manera objetiva que la primera investigación, proceso o procedimiento ha sido deficientemente realizado.

Más allá de que la sentencia emitida haya sido bien recibida por diversos sectores, consideramos que no por ello se libera de algunos aspectos polémicos en relación con la misma o con lo que argumenta.

El principal de todos ellos creemos que tiene que ver con el uso del recurso de agravio especial y la justificación que del mismo ha hecho nuestro Colegiado. Que sepamos, dicho medio impugnatorio fue creado en la senten- 
cia recaída en el Exp. 02663-2009-PHC/TC (caso Edwin Walter Martínez Moreno $)^{10}$ como una forma de garantizar del respeto al art. 8 de la Constitución Política del Estado que, como bien se conoce, establece como deber prioritario del Estado el combate y sanción del tráfico ilícito de drogas, lo que supone que los casos vinculados a este tipo de delito son los que justifican la procedencia del recurso de agravio contra sentencias estimatorias.

En el presente caso, si bien se ha venido investigando a la señora Nadine Heredia por delito de lavado de activos, dicho ilícito aparece configurado de manera autónoma, no como un delito vinculado al tráfico ilícito de drogas. La idea que se tuvo al crear el impugnatorio atípico que aquí se comenta (y basta con revisar la ejecutoria antes mencionada para corroborarlo) fue la de permitir el cuestionamiento de sentencias constitucionales que comprometieran el art. 8 de la Constitución, lo que de hecho puede producirse en los casos de tráfico ilícito de drogas configurados de manera autónoma o de lavado de activos empero vinculados al primer ilícito. Ello, reiteramos, no ha sucedido precisamente en el caso examinado.

Lo dicho, por supuesto no significa tampoco que el proceso constitucional cuestionado no haya podido ser objetado. Sin embargo, somos de la idea que si su tramitación o el resultado en que finalmente desembocó resultaban objetables desde la perspectiva constitucional, el instrumento utilizado no debió ser precisamente el del recurso de agravio especial o atípico, sino el de un proceso constitucional contra otro proceso constitucional (en este caso, un eventual amparo contra habeas corpus). Si el camino seguido lo fue por un tema de mayor rapidez o celeridad es otra cosa. Pero rigurosamente hablando, no era exactamente el que correspondía.

\section{PROCESOS CONSTITUCIONALES ORGÁNICOS}

\section{Sobre el condicionamiento del derecho a la educación a instancias de obligaciones de tipo económico (Exp. 001 1-2013-PI/TC. Caso Colegio de Abogados de Lima Norte)}

El 5 de enero de 2015 el Tribunal Constitucional dió a conocer una sentencia especialmente importante con motivo del proceso de inconstitucionalidad interpuesto por el Colegio de Abogados de Lima Norte contra el Congreso de la República y en el que se venía cuestionando el art. 2 de la Ley 29947 de Protección a la Economía Familiar.

10 Cfr. Sáenz Dávalos (2011: 692-693). 
De acuerdo con el citado dispositivo, los institutos, escuelas superiores, universidades y escuelas de posgrado públicas y privadas no pueden condicionar ni impedir la asistencia a clases, a evaluaciones ni la atención de los reclamos formulados al pago de las pensiones en el ciclo lectivo que se viene cursando. En todo caso, las instituciones educativas pueden retener los certificados correspondientes al periodo no pagado siempre que ello haya sido informado a los usuarios en el momento de la matricula y se proceda a la matricula del ciclo siguiente previa cancelación de la deuda. Añadiéndose que la tasa de interés para las moras sobre pensiones no pagadas no podrán superar la tasa de interés interbancario dispuesta por el Banco Central de Reserva del Perú. La norma tampoco permite que se condicione la rendición de evaluaciones del ciclo lectivo en curso a los alumnos que se encuentren desempeñándose como deportistas calificados de alto nivel a la asistencia presencial a clases que colisionen con las horas de entrenamiento o con los eventos deportivos donde participan.

Lo que la citada norma pretendía en el fondo era dar solución a un problema muy frecuente en el ámbito de las instituciones educativas y que se traducía en la afectación directa del servicio educativo para quienes no cumplieran oportunamente con el pago de sus obligaciones económicas. Muchos venían cuestionando esto como un exceso y la norma buscó dar una solución al respecto.

Los demandantes, sin embargo han entendido que la fórmula adoptada colisiona con una serie de derechos fundamentales (la libre iniciativa privada, las obligaciones derivadas del servicio educativo, la libertad de empresa) y por ello demandan su inconstitucionalidad.

El Colegiado emitiría sentencia desestimando la demanda tras un examen principalmente centrado en lo que representa la educación universitaria, sea esta pública o privada. En este contexto y con independencia de las invocaciones que sobre derechos y principios involucrados formularía la parte demandante, se consideraría que la norma impugnada no vulnera el derecho a la libre iniciativa privada, ya que no afecta a la libre creación, sino a aspectos específicos de la auto-organización en el marco de relaciones establecidas entre la entidad educativa y sus discentes-usuarios. Tampoco se afectaría la libertad de contratación, habida cuenta que por tratarse la educación de un servicio público donde no existe posibilidad de negociación entre las partes, el Estado tiene la posibilidad de intervenir, como en efecto lo ha hecho, sin que tal intervención pueda ser calificada per se como inconstitucional.

En relación con la libertad de empresa, el derecho de asociación y la autonomía universitaria, el Tribunal estimaría que aunque la norma cuestionada si efectúa limitaciones desde la perspectiva auto-organizativa, no por ello ha de estarse a su necesaria inconstitucionalidad, ya que debe evaluarse si tal 
restricción resulta o no justificada y en el presente caso queda claro que en atención a los objetivos que presupone el derecho a la educación y el moderado nivel en la intensidad de las restricciones realizadas, sí lo está, con lo cual se descartaría también su inconstitucionalidad.

La ejecutoria comentada sería emitida en mayoría con el voto a favor de los magistrados Urviola Hani, Miranda Canales, Blume Fortini, Ramos Núñez, Ledesma Narváez y Espinosa-Saldaña. En contra se pronunciaría el magistrado Sardón de Taboada.

Sobre el régimen jurídico de la universidad peruana y la Superintendencia Nacional de Educación Superior Universitaria (Exps. 0014-2014-PI/TC, 00162014-PI/TC, 0019-2014-PI/TC, 0007-2015-PI/TC)

Sentencia particularmente opinable sería publicada por el Tribunal Constitucional el 12 de noviembre de 2015 con motivo de diversos procesos de inconstitucionalidad acumulados interpuestos por el Colegio de Abogados de Lima, el Colegio de Abogados de Lima Norte, congresistas de la República y 6453 ciudadanos contra el Congreso de la República.

Materia objeto de cuestionamiento serían una serie de normas contenidas en la Ley Universitaria 30220 (concretamente los arts. 1, 8-9, 11-17, 19$23,27-28,35,56-57,59,78,84,109,115-116$ y 120-121; las disposiciones complementarias transitorias primera, segunda, cercera, cuarta, y decimoprimera; la disposición complementaria final sexta y la disposición complementaria derogatoria única).

Con independencia de algunos aspectos en estricto específicos, dos serían los temas principales que se analizarían en la sentencia: el relativo a la autonomía de las universidades y la creación y competencias conferidas a la llamada Superintendencia Nacional de Educación Superior (SUNEDU). En este contexto, el Colegiado se pronunciara en mayoría (con los votos de Urviola Hani, Miranda Canales, Ramos Núñez, Ledesma Narváez y Espinosa-Saldaña) declarando conformes con la Constitución la totalidad de normas impugnadas, mientras que tres magistrados constitucionales formularon sendos votos singulares, por considerar inconstitucionales algunas normas (como en el caso del magistrado Miranda Canales en relación con el art. 84 de la Ley) o la totalidad de las mismas (como en el caso de los magistrados Blume Fortini y Sardón de Taboada)

En cuanto a lo primero, estimaría la sentencia que la autonomía universitaria no resulta vulnerada o amenazada por el hecho de que el legislador realice una regulación que incida sobre aspectos propios de la misión que la Constitución ha otorgado a dichas instituciones públicas o privadas. La vulneración o amenaza se daría si la incidencia regulatoria fuese desproporcionada o 
arbitraria en las competencias conferidas a las universidades, despojándolas de sus atribuciones, o limitándolas en forma irrazonable, lo que no se apreciaría precisamente en las normas objeto de cuestionamiento.

En cuanto a lo segundo, la ejecutoria destacaría que la eventual creación de una entidad como la SUNEDU ya había sido anticipada como una necesidad en una sentencia emitida por un anterior Colegiado del propio Tribunal (Exp. 0017-2008-PI/TC, caso 6515 Ciudadanos). Por lo demás, en nuestro ordenamiento jurídico existen una serie de organismos reguladores que tienen a su cargo la supervisión de diversos servicios públicos, sin que por dicho motivo se alegue inconstitucionalidad alguna, como ocurre en el presente caso con la SUNEDU y el servicio de educación universitaria. En tales circunstancias, la creación de la citada entidad no vulnera por sí misma la autonomía universitaria.

Aunque proclamadas en abstracto las citadas aseveraciones podrían en efecto ser asumidas como inobjetables, el hecho concreto es que analizados en detalle los contenidos de las normas objeto de cuestionamiento difícilmente se podría validar su presunta conformidad con la Constitución. En efecto, pensar que mediante una ley puede procederse al cese inmediato de todas las autoridades universitarias, sin respetar plazos ni procesos libremente llevados a efecto, no parece ser precisamente una muestra de respeto hacia la autonomía universitaria, por mas ropajes que se le quiera dar. Que las universidades no hayan venido funcionando de la manera más adecuada o eficiente es una realidad que nadie en su sano juicio se atrevería a negar, pero de allí a pensar que por ello se justifica una virtual quiebra institucional por vía legislativa es algo difícil de aceptar.

En cuanto a la SUNEDU, es totalmente cierto que su existencia ya había sido validada por una anterior ejecutoria del mismo Tribunal, y visto en perspectiva lo que representa el control del servicio educativo, no aparece negativa. El problema, sin embargo, no es ese, sino el del tipo de facultades que se le ha conferido y que en muchos casos tienen poco que ver con lo que se espera de un organismo propiamente regulador, como ocurre con las recomendaciones que emite en relación con las responsabilidades disciplinarias de las autoridades universitarias, el régimen de infracciones y sanciones que utiliza o la propia facultad de la que se encuentra investida para fiscalizar la calidad del ejercicio profesional que, por supuesto, y sin dejar de ser loable, representa una abierta vulneración de las competencias atribuidas a los colegios profesionales.

Estos aspectos, como otros igual de polémicos, como ocurre con los relativos a la imposición de límites en la edad para jubilarse en la docencia universitaria o los requisitos de graduación especializada como únicos referentes para acceder a la docencia, que no parecen responder ni a la realidad universitaria 
en nuestro país ni al estándar de lo que supone representa un buen docente, convierten a esta ejecutoria en una de las más opinables del actual Colegiado.

\section{BALANCE DE LA ACTUACION DEL NUEVO PLENO A LA LUZ DE SU JURISPRUDENCIA}

Como indicábamos al inicio de este trabajo, el nuevo Pleno arranco sus tareas con buen auspicio y premunido de una legitimidad indiscutible.

En este contexto, y aunque es incuestionable que cada nueva conformación del Tribunal Constitucional tiene la plena libertad de ratificar líneas jurisprudenciales preexistentes o, al contrario, dejarlas sin efecto en todo o en parte, no deja de ser menos cierto que ello requiere tomas de posición suficientemente sólidas en argumentación y perspectiva.

El dilema con el actual Pleno es que si nos atenemos al análisis de sus principales sentencias (algunas de las cuales aquí se han seleccionado) se puede observar que muy pocas veces ha logrado generar una posición rigurosamente unánime o consensuada ${ }^{11}$. La adopción de posturas en relación con diversos temas, a pesar de haberse logrado en función de mayorías, por lo general ha estado acompañada de frecuentes disidencias probablemente como consecuencia de algunas líneas de raciocinio no muy convincentes o, en otras, de una no muy justificada voluntad de marcar distancias con anteriores composiciones del mismo Tribunal. Y es allí donde entendemos que radica uno de los principales inconvenientes. Aunque no está en discusión la probidad y versación de los nuevos magistrados, el afán de dejar sentado un perfil propio le ha hecho apartarse de una manera bastante radical de la imagen activista y bastante tuitiva que caracterizo a otras conformaciones.

Precedentes como los recaídos en los Expedientes 0987-2014-PA/TC (caso Francisca Vásquez Romero) o 05057-2013-PA/TC (caso Rosalía Beatriz Huatuco Huatuco), probablemente estructurados con la mejor de las buenas intenciones, han terminado sin embargo por restar la posición que desde la perspectiva tutelar caracterizó por años al Tribunal Constitucional, pues lo que antes solía generar una frondosa jurisprudencia y desarrollos bastante interesantes en materia de derechos, hoy se ve limitado por una notoria ten-

11 Lo dicho no significa, por cierto, que no hayan existido discrepancias en el interior de otros Plenos o composiciones del mismo Tribunal. Sin embargo, estas últimas no solo no fueron la regla, sino que, en los grandes casos, por lo general se generaron consensos bastante más frecuentes, ofreciéndose con ello la imagen de unos Colegiados bastante más sólidos. 
dencia hacia la autorestricción, lo que se ve acentuado si se toma en cuenta la práctica expansiva de dichas ejecutorias y que ha buscado aplicarse a supuestos para los que no necesariamente fueron creadas (un caso concreto es el de la aplicación de la sentencia interlocutoria denegatoria a la casi totalidad de causales de improcedencia previstas en el Código Procesal Constitucional).

Por supuesto, tampoco estamos diciendo con esto que las cosas hayan sido absolutamente óptimas en el pasado y que no existan aportes en el presente (la reseña expuesta da cuenta de algunos de ellos y creemos que muy importantes), pero es un hecho que si una imagen se había ganado el Tribunal Constitucional a fuerza del trabajo jurisdiccional emprendido ciertamente más por unos Plenos que por otros, era la de un órgano bastante más protector de lo que representaba y aún representa el Poder Judicial. Esta línea distintiva cada vez se observa menos visible.

Queda claro que la realidad descrita no debe asumirse como una tendencia indefinida ni tampoco como la imposibilidad de que en el futuro no puedan generarse consensos o adoptarse nuevas posturas, pero si nos atenemos a lo que ha venido sucediendo hasta el cierre del presente calendario, las cosas son en esencia como aquí se describe.

Del Tribunal Constitucional y de sus actuales magistrados, depende el camino que emprender.

\section{BIBLIOGRAFÍA}

Sáenz Dávalos, Luis R. (2010). El Tribunal Constitucional peruano durante los años 2008-2009: balance jurisprudencial. Anuario Iberoamericano de Justicia Constitucional, 14, 615-656.

- (2011). El Tribunal Constitucional peruano durante el año 2010: balance jurisprudencial. Anuario Iberoamericano de Justicia Constitucional, 15, 677-714.

- (2012). El Tribunal Constitucional Peruano durante el año 2011: balance jurisprudencial. Anuario Iberoamericano de Justicia Constitucional, 16, 591-642.

- (2014). El Tribunal Constitucional peruano durante el año 2013: balance jurisprudencial. Anuario Iberoamericano de Justicia Constitucional, 18, 621-636. 